\title{
A Case Report of Angioplasty and Stenting Experience for Peripheral Arte- rial Disease of the Lower Limbs at Annapurna Neurological Institute
}

\author{
Sandeep Raj Pandey ${ }^{1}$, Anik Jha ${ }^{2}$, Sudikchya Acharya ${ }^{2}$, Sudan Dhakal ${ }^{2}$ \\ ${ }^{1}$ Department of Vascular Surgery, Annapurna Neurological Institute and Allied Sciences, Maitighar,Kathmandu, Nepal \\ ${ }^{2}$ Department of Neurosurgery, Annapurna Neurological Institute and Allied Sciences ,Maitighar, Kathmandu, Nepal
}

\section{CORRESPONDENCE}

\section{Dr.Sandeep Raj Pandey}

Department of Vascular Surgery

Annapurna Neurological Institute

and Allied Sciences,

Maitighar, Kathmandu, Nepal

Email :sandeeprajpandey@gmail.com

\section{ARTICLE INFO}

Article History

Submitted: 01 November, 2020

Accepted: 18 December, 2020

Published: 8 February,2021

Source of support: None

Conflict of Interest: None

Copyright : CThe Author(S) 2020

This is an open access article under the Creative Common Attribution

license CC-BY 4.0

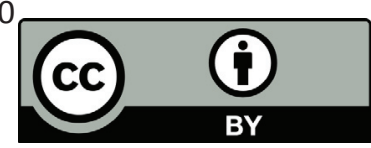

\begin{abstract}
Atherosclerosis leading to stenosis or blockage in the major vessels of lower extremities causes peripheral arterial disease(PAD). PAD may be asymptomatic in early stage. But in late stage PAD present in the form of intermittent claudication (IC) or critical limb ischaemia (CLI) . The Fontaine classification is commonly used to measure the severity of disease which is staged from I-asymtomatic to IV-gangrene. PAD can be treated by medical, endovascular and surgical management
\end{abstract}

The purpose of this case report is to consider the effectiveness of primary stenting as a treatment management for peripheral artery disease of the lower extremities.

Key words: Angioplasty; Stenting; Peripheral arterial disease.

\section{INTRODUCTION}

Atherosclerosis has been seen as a major cause of cardiovascular disease. Atherosclerosis leading to stenosis or blockage in the major vessels of lower extremities causes peripheral arterial disease(PAD). ${ }^{1}$ PAD may be asymptomatic in early stage. But in late stage PAD present in the form of intermittent claudication (IC) or critical limb ischaemia $(\mathrm{CLI}) .^{2}$ The Fontaine classification is commonly used to measure the severity of disease ${ }^{3}$ which is staged from I-asymtomatic to IV-gangrene. For scientific publications Rutherford-Baker (RB) classification is a better guide ${ }^{4}$ as Fontaine classification is mainly used clinically. RB categorized 0-asymptomatic to 6-major tissue loss.

Suspected PAD is initially evaluated by ankle-brachial index $(A B I) .{ }^{5}$ People with clinical signs of PAD \& a low $A B I$ may be referred for imaging (duplex ultrasound or angiography) to measure the anatomical location and extent of disease and determine the suitability of treatment according to the severity of their symptoms. ${ }^{6}$ Atherosclerotic disease patterns in the lower extremities are classified by the Inter-Society Consensus (TASC II) according to anatomic distribution and the number and nature of lesions (stenosis, occlusion). ${ }^{7}$ TASC again divied into type $A$ lesions to Type $D$ lesions as below:

\section{Type A lesions}

- Aortoiliac - unilateral or bilateral stenoses of CIA; unilateral or bilateral single short $(\leq 3 \mathrm{~cm})$ stenosis of EIA.

- Fempop - single stenosis $\leq 10 \mathrm{~cm}$ in length; single occlusion $\leq 5 \mathrm{~cm}$ in length.

Type B lesions

- Aortoiliac - short $(\leq 3 \mathrm{~cm})$ stenosis of infrarenal aorta; unilateral CIA occlusion; single or multiple stenoses totalling $3 \mathrm{~cm}$ to $10 \mathrm{~cm}$, involving the EIA and not extending into the CFA; unilateral EIA occlusion not involving the origins of the EIA or CFA. 
- Fempop - multiple lesions (stenoses or occlusions), each $\leq$ $5 \mathrm{~cm}$; single stenosis or occlusion $\leq 15 \mathrm{~cm}$ not involving the infrageniculate popliteal artery; single or multiple lesions in the absence of continuous tibial vessels to improve inflow for a distal bypass; heavy calcified occlusion $\leq 5 \mathrm{~cm}$ in length; single popliteal stenosis.

\section{Type C lesions.}

- $\quad$ Aortoiliac - bilateral CIA occlusions; bilateral EIA stenoses $3 \mathrm{~cm}$ to $10 \mathrm{~cm}$ long and not extending into the CFA; unilateral EIA stenosis extending into the CFA; unilateral EIA occlusion that involves the origins of internal iliac and/or CFA; heavily calcified unilateral EIA occlusion with or without involvement of origins of internal iliac and/or CFA.

- Fempop - multiple stenoses or occlusions totalling $>15$ $\mathrm{cm}$, with or without heavy calcification; recurrent stenoses or occlusions that need treatment after two endovascular interventions.

\section{Type D lesions}

- Aortoiliac - infrarenal aortoiliac occlusion; diffuse disease involving the aorta and both iliac arteries requiring treatment; diffuse multiple stenoses involving the unilateral CIA, EIA and CFA; unilateral occlusions of both $\mathrm{CIA}$ and EIA; bilateral occlusions of EIA.

- Fempop - chronic total occlusions of CFA or SFA (> $20 \mathrm{~cm}$, involving the pop artery); chronic total occlusion of pop artery and proximal trifurcation vessels.

There has been a recent update of the TASC to include a classification for below-the-knee arteries. ${ }^{8}$

- TASC A lesions - single focal stenosis, $\leq 5 \mathrm{~cm}$ in length, in the target tibial artery with occlusion or stenosis of similar or worse severity in the other tibial arteries.

- TASC B lesions - multiple stenoses, each $\leq 5 \mathrm{~cm}$ in length, or total length $\leq 10 \mathrm{~cm}$ or single occlusion $\leq 3 \mathrm{~cm}$ in length, in the target tibial artery with occlusion or stenosis of similar or worse severity in the other tibial arteries.

- $\quad$ TASC C lesions - multiple stenoses in the target tibial artery and/or single occlusion with total lesion length $>10 \mathrm{~cm}$ with occlusion or stenosis of similar or worse severity in the other tibial arteries.

- $\quad$ TASC D lesions - multiple occlusions involving the target tibial artery with total lesion length $>10 \mathrm{~cm}$, dense lesion calcification or non-visualisation of collaterals. The other tibial arteries are occluded or have dense calcification. PAD can be treated by medical, endovascular and surgical management(9)

\section{MEDICAL MANAGEMENT}

Smoking cessation, losing weight and increasing physical activity can halt the process of atherosclerosis.10 Clinicians may also prescribe secondary measures to target hypertension and hypercholesterolaemia, such as cholesterol-lowering agents (statins), antihypertensives and antiplatelets. ${ }^{11}$ All patients with PAD should receive antiplatelet treatment (clopidogrel $75 \mathrm{mg} /$ day or aspirin 75 $\mathrm{mg} /$ day to $150 \mathrm{mg} /$ day in case of clopidogrel intolerance or side effects). Can add cilostazole 50-100 mg twice daily as an adjunctive.

\section{ENDOVASCULAR AND SURGICAL MANAGEMENT}

Endovascular and surgical interventions are available in cases where medical management is not suitable or effective or in severe cases of PAD. Endovascular interventions include percutaneous transluminal angioplasty (PTA) \& surgical includes open techniques as endarterectomy $\&$ bypass.

In PTA an artery, usually the femoral artery, is cannulated; a guidewire inserted under x-ray control; and a deflated balloon catheter inserted and pushed forward along the guidewire to the site(s) of obstruction. Inflation of the balloon then opens up the stenosis or occlusion. In addition, physicians may insert a cylindrical piece of metal mesh called a stent at the site where the artery has been dilated with the aim of holding the narrowing open for the future. PTA can be used to either dilate shorter stenosis or recanalise an entire artery (12). If the blockage is not suitable for PTA and stenting, patients may undergo an open surgical intervention such as an open bypass operation. This involves redirecting blood through a bypass (usually a healthy vein or a graft of synthetic material). PTA offers several potential advantages over open surgical revascularisation. People undergoing PTA receive local anaesthesia, so even those at high risk of general anaesthesia can still receive treatment. There are few complications, and the recovery is quick, so people can usually return to normal activity within 24 to 48 hours 13

\section{CASE REPORT}

A 67 year male presented with with severe claudication(Fontiane stage II B;Rutherfors category 3) of right leg at my center. His pedal pulses were absent. He had already undergone CT-angio which revealed aorto-iliac \& b/l lower limbs atherosclerotic disease9(TASC A lesion). There was small outpouching in right $\mathrm{CIA}(9 \times 4 \mathrm{~mm})$. Right external iliac artery(EIA) showed 75\% stenosis with 23 
$\mathrm{mm}$ in length. Right distal superficial artery (SFA) showed long segment $30 \mathrm{~cm}$ focal complete total occlusion (СТО) with distal reformation of politeal artery via collaterals.

Anterior tibial artery (ATA) \& posterior tibial artery (PTA) showed normal course \& caliber (Fig. 1 \& 2). He underwent right SFA angioplasty with $0.035 \& 0.014$ hitorque $300 \mathrm{~cm}$ wires \& $5 \mathrm{~mm} \times 150 \mathrm{~mm} \times 135 \mathrm{~cm}$ balloons via 35 II pta catheters percutaneously via left common feoral artery(CFA) access. During ballooning in distal SFA, there was dissection which was treated with stent (Absolute pro II, Peripheral self expanding stent system, $5 \times 150 \mathrm{~mm}, 135 \mathrm{~cm}$ ). (Fig. 3) EIA angioplasty with complete CIA \& EIA stenting by Abbott vascular, Absolute pro II $, 8 \times 120 \mathrm{~mm}, 135 \mathrm{~cm}$ stent was done(Fig.4).Good groin compression achieved.300 mg Clopidogrel was given per oral on table.

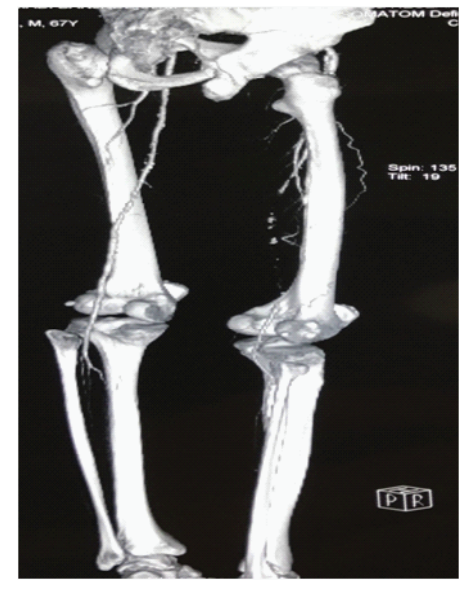

Fig.1 SFA CTO $(30 \mathrm{~cm})$

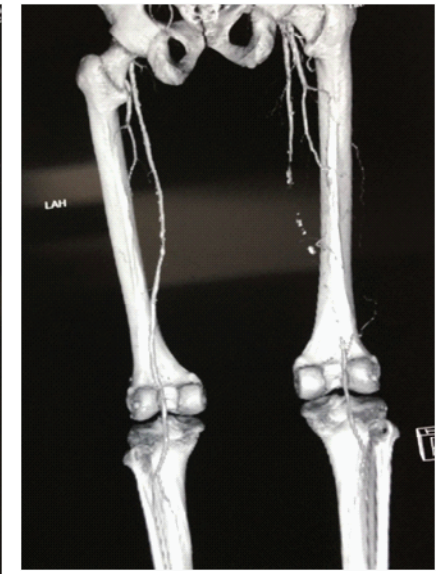

Fig.2 SFA CTO $(30 \mathrm{~cm})$

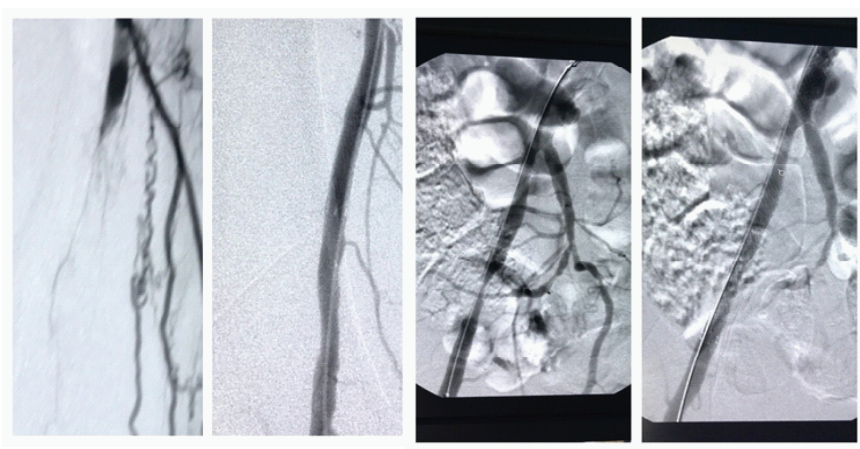

Fig.3 SFA recanalization Fig.4 lliac artery recanalization

Patient's pedal pulses were palpable on table. No post op groin complications.Patient discharged on next day with dual antiplatelets \& statin.Patient was symptomically better on a week follow up. No claudication was found at all.

\section{Discussion}

Clinical outcomes in PAD can be improved by the current landscape for peripheral vascular interventions which includes various technologies. The use of DEB increases patency and TLR outcomes in both femoropopliteal and infrapopliteal PAD. Stenting has a rising role in both bailout and primary interventions and is particularly promising with the development of DES. Further well-designed and highly powered trials are needed to determine the ideal treatment strategies for the management of patients with PAD. ${ }^{14}$

For the stenting for peripheral artery disease of the lower extremities, the primary outcome measure was patency. Secondary measures included technical success, re-intervention, complications, hemodynamic (ankle brachial pressure index, treadmill walking distance) and clinical success or improvement according to Rutherford scale. It was anticipated, a priori, that there would be substantial differences among trials regarding the method of examination and definitions of patency or re-stenosis. Where studies reported only re-stenosis rates, patency rates were calculated as 1 minus re-stenosis rates. ${ }^{15}$

The key findings of the MAS analyses are: compared with PTA, primary stenting using self-expanding bare stents is associated with significant improvement in patency at 6,12 and 24 months in patients with superficial femoral artery. However, no statistically significant differences between primary stenting and PTA on re-interventions, clinical improvement, complications, mortality, amputations and $A B I$ were observed. Methodological differences between MAS review and the five published systematic reviews and meta-analysis of RCTs reports are summarized below:

\section{YaJun et al ${ }^{16}$}

- Only included RCTs using balloon expandable stents. MAS analysis includes both balloon and self-expandable stents.

- Included one study that was not randomized. MAS analysis only included published results of randomized trials

- Analysis based on number of evaluable patients at the chosen endpoint during follow-up. MAS analysis is based on ITT.

- $\quad$ The conclusion of significant primary patency at 6 months are influenced by one trial which was not included in the MAS review as it was a pilot trial. For MAS review, feasibility trials were excluded.

\section{Bachoo et al $^{17}$}

- Only included studies with patients with intermittent claudication. Only two studies were included and results could not be pooled for most outcomes. MAS analysis included studies with patients with intermittent claudication and critical ischemia. 


\section{Twine et al $^{18}$}

- "Analysis based on endpoint data from the individual clinical trials, which all quoted intention- to treat principle". This is not a true definition of ITT. A true definition of ITT analysed patients according to the treatment to which they were randomized. ITT is more pragmatic and preserve sample size. MAS analysis was based on a true definition of ITT.

- $\quad$ The analysis combined both balloon and self expanding stents. MAS analysis was performed according to a type of stent.

- The observed short term benefit of stenting was influenced by a trial using self expanding stent.

\section{CONCLUSION}

The past few decades have witnessed remarkable innovation in technology leading to an expanding use of endovascular therapy to treat lower extremity peripheral occlusive arterial disease of increasing severity. This has resulted in a shift away from open surgical revascularization and toward percutaneous endovascular therapy (angioplasty \& stenting) as a first option.

\section{REFERENCES}

1. Peach G, Griffin M, Jones KG, Thompson MM, Hinchcliffe RJ. Diagnosis and management of peripheral arterial disease.BMJ 2012;345:e5208.

2. 2. Peach G, Griffin M, Jones KG, Thompson MM,Hinchcliffe RJ. Diagnosis and management of peripheral arterial disease.BMJ 2012;345:e5208.

3. Fontaine R, Kim M, Kieny R. Die chirurgische Behandlung der peripheren Durch-blutungsstörungen.Helvetica Chimita Acta1954;21(5-6):499-533.

4. Rutherford RB, Baker JD,Ernst C, Johnston KW,Porter JM, Ahn S, et al.Recommended standards for reports dealing with lower extremity ischemia: revised version. Journal of Vascular Surgery1997;26(3):517-38.

5. Fowkes FGR. The measurement of atherosclerotic peripheral arterial disease in epidemiological surveys. International Journal of Epidemiology1988;17(2):248-54.

6. Scottish Intercollegiate Guidelines Network (SIGN). Diagnosis and management of peripheral arterial disease. A national clinical guideline. 2006.www.sign.ac.uk/pdf/ sign89.pdf

7. Norgren L, Hiatt WR,Dormandy JA, Nehler MR,Harris KA, Fowkes FGR.Inter-Society Consensus for the Management of Peripheral Arterial Disease (TASC II). Journal of Vascular Surgery2007;45(1):S5-67.
8. Jaff MR, White CJ, Hiatt WR,Fowkes GR, Dormandy J,Razavi $M$, et al. An update on methods for revascularization and expansion of the TASC lesion classification to include below-the-knee arteries: A supplement to the inter-society consensus for the management of peripheral arterial disease (TASC II). Catheterization and Cardiovascular Interventions2015; 86(4):611-25.

9. National Institute for Health and Clinical Excellence. Lower limb peripheral arterial disease: diagnosis and management. NICE clinical guideline 147.guidance.nice. org.uk/cg147 (accessed 14 November 2013) August 2012.

10. Hirsch AT, Treat-Jacobson D, Lando HA, Hatsukami DK. The role of tobacco cessation, antiplatelet and lipid-lowering therapies in the treatment of peripheral arterial disease. Vascular Medicine1997;2(3):43-51. Hirsch AT, TreatJacobson D, Lando HA, Hatsukami DK. The role of tobacco cessation, antiplatelet and lipid-lowering therapies in the treatment of peripheral arterial disease.Vascular Medicine1997;2(3):43-51.

11. KüglerCFA, RudofskyG.The challenges of treating peripheral arterial disease.Vascular Medicine2003;8(2):109-14.

12. White CJ, Gray WA.Endovascular therapies for peripheral arterial disease: An evidence-based review. Circulation2007;116(19):2203-15.

13. Isner J, Rosenfield K.Redefining the treatment of peripheral artery disease: role of percutaneous revascularization. Circulation 1993;88(4 pt 1):1534-57.

14. Rigved V. Tadwalkar and Michael S. Lee, "The Current State of Endovascular Intervention for Peripheral Arterial Disease".

15. Ontario Health Technology Advisory Committee -https:// pubmed.ncbi.nlm.nih.gov/23074395/

16. $\mathrm{E} Y, \mathrm{He} N$, Wang $\mathrm{Y}$, Fan $\mathrm{H}$. Percutaneous transluminal angioplasty (PTA)aloneversus PTA with balloon-expandable stent placement for short-segment femoropopliteal artery disease: a metaanalysis of randomized trials. J Vasc Interv Radiol. 2008.

17. Bachoo P, Thorpe PA, Maxwell H, Welch K. Endovascular stents for intermittent claudication. Cochrane Database Syst Rev. 2010.

18. Twine CP, Coulston J, Shandall A, McLain AD. Angioplasty versus stenting for superficial femoral artery lesions. Cochrane Database Syst Rev. 2009 